\title{
Side-by-side analysis of five clinically tested anti- EpCAM monoclonal antibodies
}

\author{
Markus Münz ${ }^{1,2}$, Alexander Murr ${ }^{1,2}$, Majk Kvesic ${ }^{1,2}$, Doris Rau ${ }^{1,2}$, Susanne Mangold ${ }^{1,2}$, Stefan Pflanz ${ }^{1,2}$, \\ John Lumsden ${ }^{1,2}$, Jörg Volkland ${ }^{1,2}$, Jan Fagerberg ${ }^{1,2}$, Gert Riethmüller ${ }^{3}$, Dominik Rüttinger ${ }^{1,2}$, Peter Kufer ${ }^{1,2}$, \\ Patrick A Baeuerle ${ }^{1,2^{*}}$, Tobias Raum ${ }^{1,2}$
}

\begin{abstract}
Background: Epithelial cell adhesion molecule (EPCAM) is frequently and highly expressed on human carcinomas. The emerging role of EpCAM as a signalling receptor and activator of the wnt pathway, and its expression on tumor-initiating cells, further add to its attractiveness as target for immunotherapy of cancer. Thus far, five conventional monoclonal IgG antibodies have been tested in cancer patients. These are murine lgG2a edrecolomab and its murine/human chimeric lgG1 antibody version, and humanized, human-engineered and fully human IgG1 antibodies 3622W94, ING-1, and adecatumumab (MT201), respectively. Here we compared all antiEpCAM antibodies in an attempt to explain differences in clinical activity and safety.
\end{abstract}

Methods: We recombinantly produced all antibodies but murine edrecolomab and investigated them for binding affinity, EpCAM epitope recognition, ADCC and CDC, and inhibition of breast cancer cell proliferation.

Results: ING-1 and 3622W94 bound to EpCAM with much higher affinity than adecatumumab and edrecolomab. Edrecolomab, ING-1, and 3622W94 all recognized epitopes in the exon 2-encoded N-terminal domain of EpCAM, while adecatumumab recognized a more membrane proximal epitope encoded by exon 5 . All antibodies induced lysis of EpCAM-expressing cancer cell lines by both ADCC and CDC with potencies that correlated with their binding affinities. The chimeric version of edrecolomab with a human Fcy1 domain was much more potent in ADCC than the murine IgG2a version. Only adecatumumab showed a significant inhibition of MCF-7 breast cancer cell proliferation in the absence of complement and immune cells.

Conclusion: A moderate binding affinity and recognition of a distinct domain of EpCAM may best explain why adecatumumab showed a larger therapeutic window in cancer patients than the two high-affinity IgG1 antibodies ING-1 and 3622W94, both of which caused acute pancreatitis.

\section{Introduction}

Epithelial cell adhesion molecule EpCAM (CD326; 17-1A antigen) was among the first human tumor-associated antigens discovered [1]. It was initially identified by the monoclonal antibody (mAb) 17-1A after immunization of mice with human colorectal cancer cells [2]. Using a similar approach, the EpCAM antigen has been identified many more times and each time given the name of the respective monoclonal antibody $[3,4]$. For a long time, EpCAM was considered a mere cell surface protein mediating homotypic cell adhesion [5-7]. This function did

\footnotetext{
* Correspondence: Patrick.baeuerle@micromet-inc.com

${ }^{1}$ Micromet AG, Staffelseestr. 2, 81477 Munich, Germany

Full list of author information is available at the end of the article
}

not well explain its frequent and high expression in primary tumors and metastases [1,3], correlation of expression with poor survival prognosis $[1,8]$, and its expression on tumor-initiating or cancer stem cells [9-12]. Only recently, EpCAM was shown to play a role in cell proliferation, signal transduction, and as a proto-oncogene [13-15]. EpCAM can undergo regulated intra-membrane proteolysis leading to release of its small intracellular domain EpICD [14]. In the cytoplasm, released EpICD combines with adaptor proteins FHL2 and $\beta$-catenin ultimately leading to formation of a large nuclear complex containing transcription factor LEF/TCF, which can turn on transcription of c-myc and cyclin genes and thereby drive cancer and stem cell proliferation [16-20].
C Biomed Central 
EpCAM has been selected as target antigen for many immunotherapeutic approaches based on either antibodies or vaccines $[1,21]$. In 2009, an anti-EpCAM trispecific antibody called catumaxomab (Removab) obtained market authorization in Europe for treatment of malignant ascites in cancer patients [22]. Several other EpCAM-directed antibodies and antibody-based constructs are at various stages of clinical development $[1,21,23]$. The first monoclonal antibody ever tested in cancer patients was the EpCAM-specific murine IgG2a antibody 17-1A produced in ascites of mice $[24,25]$. This antibody was later produced by fermentation and called edrecolomab. Clinical evaluation of the antibody was mainly done in patients with colorectal cancer, either with metastatic disease [26] or in the adjuvant setting [27]. Objective responses were achieved only in a limited number of patients with metastatic disease [26]. However, a pivotal study in patients with surgically resected colorectal cancer Dukes' stage C randomized to observation or treatment with edrecolomab showed a significant clinical benefit, i.e., reduction of recurrence and death rate, and a benign safety profile $[27,28]$. Subsequent larger studies in Europe and the USA could not confirm edrecolomab's clinical activity in the adjuvant setting [29-31].

The high immunogenicity and short serum half life of murine antibody edrecolomab prompted the development of chimeric, humanized, human-engineered and fully human anti-EpCAM antibodies all sharing the human Fc $\gamma 1$ portion. The human IgG1 isotype was selected for its superior potential of antibody-dependent cellular cytotoxicity (ADCC) and complement-dependent cytotoxicity (CDC) [32-34]. Only few patients have been treated with a human/murine chimeric version of edrecolomab, and then also in combination with GMCSF to augment effector cell function and thereby potentially enhance the efficacy of the antibody $[35,36]$. The induction of an anti-idiotypic response was also explored [36] though no positive correlation between an anti-idiotype formation and clinical response to 17-1A antibody could be established in more than 60 colorectal cancer patients [37].

The human-engineered and humanized anti-EpCAM antibodies ING-1 and 3622W94, respectively, were developed and tested in clinical phase 1 studies in cancer patients [38-40]. Both had a relatively high binding affinity for EpCAM, had a maximum tolerated dose (MTD) of $1 \mathrm{mg} / \mathrm{kg}$ bodyweight, and their dose-limiting toxicity was acute pancreatitis $[38,39,41]$. Adecatumumab (MT201) is a fully human IgG1 antibody binding with intermediate affinity to EpCAM [42]. It has so far been administered to more than 240 patients with prostate and breast cancer in two phase 1 [43-45], and two phase 2 trials [45]. No MTD has been reached at $6 \mathrm{mg} /$ $\mathrm{kg}$ when delivered as monotherapy $[44,46]$, and up to
$13 \mathrm{mg} / \mathrm{kg}$ were tolerated in a phase 1 study in combination with taxotere. Of note, no clinically manifest pancreatitis has been observed to date. Retrospective analyses indicated that a subgroup of patients with metastatic breast cancer having primary tumors expressing high levels of EpCAM showed clinical benefit by adecatumumab in terms of increased time to progression and reduced incidence of new lesions [45]. When combined with taxotere, a higher percentage of objective responses are observed with the antibody/taxotere combination than with chemotherapy alone [47].

Here, we have for the first time compared side-by-side edrecolomab in its murine and chimeric version, ING-1, 3622W94 and adecatumumab for their in-vitro biological characteristics, including binding affinity, epitope recognition, $\mathrm{ADCC}$ and $\mathrm{CDC}$, and inhibition of cancer cell proliferation. Adecatumumab was unique in that it bound to an epitope encoded by exon 5 of EpCAM, and by inhibiting proliferation of MCF-7 breast cancer cells in the absence of effector cells and complement. Our data may help to better understand the differences in tolerability and signs of clinical activity of the five monoclonal antibodies.

\section{Methods}

\section{Generation and purification of antibodies}

Edrecolomab (murine anti-EpCAM; 17-1A; Panorex) was obtained as clinical trial material produced under GMP using a murine hybridoma cell line (Centocor Inc.). Human antibody adecatumumab (MT201) was generated by phage display-guided selection and produced by $\mathrm{CHO}$ cells as described previously $[42,48]$. The murine/human chimeric version of edrecolomab, and 3622W94 (hu323/A3) and ING-1 antibodies were generated by grafting according $\mathrm{V}_{\mathrm{H}}$ and $\mathrm{V}_{\mathrm{L}}$ DNA sequences onto a human $\operatorname{IgG}_{1}$ backbone. $\mathrm{V}_{\mathrm{H}}$ sequences were cloned into pEF-dhfr and $\mathrm{V}_{\mathrm{L}}$ sequences into pEF-ada expression vectors. These antibodies were expressed in $\mathrm{CHO}$ cells and purified by FPLC affinity purification using Protein G or A. Antibodies were eluted with $100 \mathrm{mM}$ citrate buffer $\mathrm{pH} 2.3$.

\section{Cell lines expressing murine, cynomolgus and human EpCAM and respective chimera}

DHFR ${ }^{-}$Chinese hamster ovary (CHO), Kato III, MCF-7, MCF10A cells and HEK293 cells were purchased from the American Type Cell Culture Collection (ATCC, Manassas, USA). CHO lines stably expressing human EpCAM (CHO-huEpCAM), murine EpCAM (CHOmEpCAM), cynomolgus EpCAM (CHO-cynoEpCAM) and the chimera of cyno/human and murine/human EpCAM chimera were all generated by transfecting $\mathrm{CHO}$ cells with expression plasmids containing the respective cDNAs. 


\section{Construction of CDNAs}

In a first step, the cDNA encoding human EpCAM was modified by introduction of three silent recognition sites for restriction enzymes. The resulting construct allowed convenient exchange of defined human sequence fragments through their corresponding cyno equivalents in the context of the EpCAM full-length cDNA through a simple 'cut-and-paste' cloning approach. The cDNAs encoding different human/cyno EpCAM fragments were generated by gene synthesis. Chimeric constructs of verified DNA sequence were cloned into the pEF-dhfr expression vector to permit transient transfection and expression in HEK293 cells as well as stable expression in $\mathrm{CHO}$ cells.

Selection of clones and amplification of expression was performed in suspension with HyQ medium (HyClone, Logan, USA), supplemented with $20 \mathrm{nM}$ methotrexate (Sigma-Aldrich, Steinheim, Germany). Transfected $\mathrm{CHO}$ cells were cultured in $\mathrm{HyQ}$ medium supplemented with $500 \mathrm{nM}$ methotrexate at $37^{\circ} \mathrm{C}$ in a $5 \% \mathrm{CO}_{2}$ chamber.

All in vitro assays were conducted in RPMI1640 medium (Biochrom AG, Berlin, Germany) supplemented with $10 \%$ fetal calf serum (Biochrom AG, Berlin, Germany), $100 \mathrm{u} / \mathrm{ml}$ penicillin and $100 \mu \mathrm{g} / \mathrm{ml}$ streptomycin (Biochrom AG, Berlin, Germany), $50 \mu \mathrm{M} 2$-mercaptoethanol (Invitrogen, Gaithersburg, MD), 1\% nonessential amino acids (Biochrom AG, Berlin, Germany), $1 \mathrm{mM}$ sodium pyruvate (Biochrom AG, Berlin, Germany), and $10 \mathrm{mM}$ HEPES buffer (Biochrom AG, Berlin, Germany). Additionally, for MCF-7 cells $10 \mu \mathrm{g} / \mathrm{ml}$ insuline (sigma) was added and MCF10A cells were cultured as recommended by ATCC.

\section{ADCC assay}

Kato III target cells grown under regular culture conditions were trypsinized for $5 \mathrm{~min}$, sedimented by centrifugation and resuspended in culture medium to a concentration of $10^{6}$ cells per ml. Cells $\left(1 \times 10^{6}\right)$ were labelled by incubation with BATDA (Bis-(acetoxymethyl) 2,2':6',2"-terpyridine-6-6"-dicarboxylate), the hydrophobic esterified form of TDA, which diffuses readily through the cell membrane of viable cells and accumulates as membrane impermeable TDA inside the target cells due to hydrolyzation by intracellular esterases for 30 min at $37^{\circ} \mathrm{C}$. After centrifugation at $350 \mathrm{~g}$ for 5 min cells were washed in medium 5 times. 5000 labelled cells/well resuspendend in medium were seeded into a 96-well plate as targets. Separately, peripheral blood mononuclear cells (PBMC) were prepared following conventional procedures (enriched by Ficoll-Hypaque gradient centrifugation), washed and resuspended at $6 \times 10^{6}$ per $\mathrm{ml}$. Equal volumes of target and effector cell suspensions were mixed resulting in a final ratio of effector to target cells (E : T) of 50:1. This was followed by addition of an antibody solution, previously diluted in a 1:4 series, resulting in a final concentration ranging from 0.2 to $50,000 \mathrm{ng} / \mathrm{ml}$. Cells were then incubated for $2.5 \mathrm{~h}$ at $37^{\circ} \mathrm{C}$. After centrifugation at $150 \mathrm{~g}$ and $3 \mathrm{~min}, 20 \mu \mathrm{l}$ of the supernatant were added to $100 \mu \mathrm{l}$ Europium and incubated for $10 \mathrm{~min}$ for chelate formation. Quantification was performed subsequently by time-resolved fluorometry with a plate reader (WALLAC 1420 VIC$\mathrm{TOR}^{2}$ ). The measured signal correlates directly with the amount of lysed cells. $\mathrm{EC}_{50}$ values are determined for each measurement using the four-parametric logistic regression model for the evaluation of sigmoidal doseresponse curves. All experiments were performed in triplicate.

\section{CDC assay}

KATO III cells grown under regular culture conditions were trypsinized for $5 \mathrm{~min}$ and resuspended in RPMI medium at a concentration of $10^{6}$ cells per $\mathrm{ml}$ of media. Cells were labelled with BATDA as described in the ADCC section. To each $160 \mu \mathrm{l}$ of cell suspension, $20 \mu \mathrm{l}$ of cold human serum and $20 \mu \mathrm{l}$ of the respective antibody dilution were added. Heat-inactivated human serum was used as control. After incubation of the cell cultures for $45 \mathrm{~min}$ at $25^{\circ} \mathrm{C}$, cells were sedimented and analyzed as described above in the ADCC section. All experiments were performed in triplicates.

\section{Epitope mapping}

For standard binding analysis, $1 \times 10^{5}$ to $2 \times 10^{5}$ cells were incubated with the respective antibody at concentrations ranging from 0 to $50 \mu \mathrm{g} / \mathrm{ml}$ in FACS buffer in a total volume of $50 \mu \mathrm{l}$ for $30 \mathrm{~min}$ at $4^{\circ} \mathrm{C}$. Thereafter, cells were washed twice in FACS buffer and incubated with FITClabeled secondary antibody (Dianova Cat. No. DIA 920) for additional $30 \mathrm{~min}$ at $4{ }^{\circ} \mathrm{C}$. After two washing steps in FACS buffer, 10,000 to 20,000 events were analyzed.

\section{Cell proliferation assay}

MCF-7 and MCF10A cells grown under regular growth conditions were trypsinized and seeded in the adequate medium at 3,000 cells/well in a 96-well flat bottomed plate. The following day, media was replaced with 100 $\mu \mathrm{l}$ media containing the respective antibodies at a concentration of $50 \mu \mathrm{g} / \mathrm{ml}$. Cell proliferation was measured at the indicated time points using either the CyQUANT Cell Proliferation Assay Kit (Invitrogen) or Cell Proliferation Reagent WST-1 (Roche) according to the manufacturers' instructions.

\section{Determination of binding constants}

Biacore analysis was performed using a Biacore 3000 reader (Applied Biosystems, Uppsala, Sweden). Soluble, 
recombinant extracellular domain of human EpCAM was produced and purified from the supernatant of stably transfected $\mathrm{CHO}$ cells [48]. EpCAM protein was coated to CM5 flow cells (Becton Dickinson) using the Amine Coupling Kit as described by the manufacturer. Binding studies were performed in a running buffer containing $10 \mathrm{mM}$ HEPES, pH 7.4, $150 \mathrm{mM} \mathrm{NaCl}, 3.4 \mathrm{mM}$ EDTA and $0.005 \%$ surfactant (P-20). KD and on/off rate constants were determined from sensorgrams collected with five different antibody concentrations.

\section{Results}

\section{Binding Affinities}

Binding affinities of the five recombinant antibodies was determined by surface plasmon resonance spectroscopy (BiaCore). Equilibrium dissociations constants $\left(\mathrm{K}_{\mathrm{D}}\right.$ values) for binding to recombinant EpCAM coated on Biacore sensor chips were 1.5 and $2.1 \mu \mathrm{M}$ for edrecolomab and chimeric edrecolomab, respectively, $100 \mathrm{nM}$ for adecatumumab, and 190 and $160 \mathrm{pM}$ for 3622W94 and ING-1, respectively (Table 1 ). $\mathrm{K}_{\mathrm{D}}$ values and onand off-rate constants confirmed earlier data showing that 3622W94 and ING-1 were of higher affinity for EpCAM than adecatumumab and edrecolomab. Onrates of mAbs were rather similar, with adecatumumab showing the fastest on-rate. The two highest affinity mAbs, 3622W94 and ING-1 had very slow off-rates translating into a prolonged binding to the EpCAM target.

\section{Binding Domains on EpCAM}

A crude mapping of binding domains on EpCAM was done for the antibodies by using $\mathrm{CHO}$ cells expressing either human, cynomolgus monkey, or two human/ monkey chimeric EpCAM proteins (Figure 1a). The two chimeric proteins exchanged human and monkey sequences in the middle of exon 3 , which is encoding the thyroglobulin-like repeat of EpCAM. While all four antibodies bound to $\mathrm{CHO}$ cells expressing human EpCAM in FACS analysis (Figure 1b, top panel), the only antibody binding to all four $\mathrm{CHO}$ cell lines was 3622W94, indicating cross-reactivity with monkey EpCAM. All mAbs but adecatumumab bound to cells with a human $\mathrm{N}$-terminal domain (third panel), while adecatumumab apparently recognized the C-terminal region 2 of human EpCAM (fourth panel).

A further mapping experiment used $\mathrm{CHO}$ cells expressing chimera between human and murine EpCAM (Figure 1c). Cells expressing murine EpCAM were no longer bound by mAb 3622W94. Edrecolomab, 3622W94 and ING-1 all showed robust binding in FACS to $\mathrm{CHO}$ cells expressing chimera that preserved the $\mathrm{N}$-terminal sequence encoded by human exon 2 (i. e., HHM, HMH and HMM). As an example, binding of ING-1 in FACS scans to the various transfected CHO cells is shown in Figure 1D. Exon 2 encodes a small sequence around amino acid position 40, which is divergent between human, monkey and mouse EpCAM (Figure 1e). The underlined sequence does best explain the differences in species crossreactivity and may therefore represent part of the binding epitope for antibodies 3622W94, ING-1 and edrecolomab.

Binding of adecatumumab to a more C-terminal domain of human EpCAM (see Figure 1b) was supported by analysis using the murine/human chimeric EpCAM proteins. Only CHO cells expressing chimera containing sequences encoded by human EpCAM exons 4-9 were bound by adecatumumab (Figure 1c).

\section{Binding of Adecatumumab to an Exon 5-encoded Sequence of Human EpCAM}

The binding site of adecatumumab in the C-terminal portion of EpCAM was further analyzed by HEK293 cells expressing chimera between human and cynomolgus EpCAM. Human and cynomolgus monkey EpCAM are highly conserved in this portion with major deviations

Table 1 Summary of characteristics of five clinically tested anti-EpCAM monoclonal antibodies analyzed side by side

\begin{tabular}{|c|c|c|c|c|c|c|c|c|}
\hline \multirow[t]{2}{*}{ Antibody } & \multicolumn{3}{|c|}{$\begin{array}{l}\text { Binding Affinity } \\
{[\mathrm{nM}]}\end{array}$} & \multirow[t]{2}{*}{$\begin{array}{l}\text { Binding } \\
\text { Domain }\end{array}$} & \multirow{2}{*}{$\begin{array}{c}\text { ADCC } \\
\text { Mean } \mathrm{EC}_{50} \text { in } \\
{[\mathrm{ng} / \mathrm{ml}]}\end{array}$} & \multirow{2}{*}{$\begin{array}{c}\text { CDC } \\
\text { Mean at } 20 \\
\mu \mathrm{g} / \mathrm{ml}[\%]\end{array}$} & \multirow[t]{2}{*}{$\begin{array}{c}\text { Inhibition of MCF-7 Breast Cancer } \\
\text { Cell Proliferation }\end{array}$} & \multirow[t]{2}{*}{$\begin{array}{l}\text { Tolerability in } \\
\text { Clinical Trials }\end{array}$} \\
\hline & $\mathrm{K}_{\mathrm{D}}$ & $\begin{array}{c}\mathrm{K}_{\mathrm{on}} \\
{[\mathrm{M} / \mathrm{s}]}\end{array}$ & $\begin{array}{c}K_{\text {off }} \\
{[1 / s]}\end{array}$ & & & & & \\
\hline Edrecolomab & 1530 & $\begin{array}{l}2.81 \times \\
10^{4}\end{array}$ & 0.043 & Exon 2 & 264 & 33 & Not Significant & High \\
\hline $\begin{array}{c}\text { Chimeric } \\
\text { Edrecolomab }\end{array}$ & 2095 & $\begin{array}{l}1.67 \times \\
10^{4}\end{array}$ & 0.035 & Exon 2 & 671 & 60 & Not Significant & High \\
\hline $3622 W 94$ & 0.19 & $\begin{array}{l}9.49 \times \\
10^{4}\end{array}$ & $\begin{array}{c}1.8 \times \\
10^{-5}\end{array}$ & Exon 2 & 38 & 70 & Not Significant & Low (Pancreatitis) \\
\hline ING-1 & 0.16 & $1.96 \times$ & $\begin{array}{c}3.2 \times \\
10^{-5}\end{array}$ & Exon 2 & 14 & 63 & Not Significant & Low (Pancreatitis) \\
\hline Adecatumumab & 91 & $\begin{array}{l}3.46 \times \\
10^{5}\end{array}$ & 0.0316 & Exon 5 & 175 & 29 & Yes & High \\
\hline
\end{tabular}




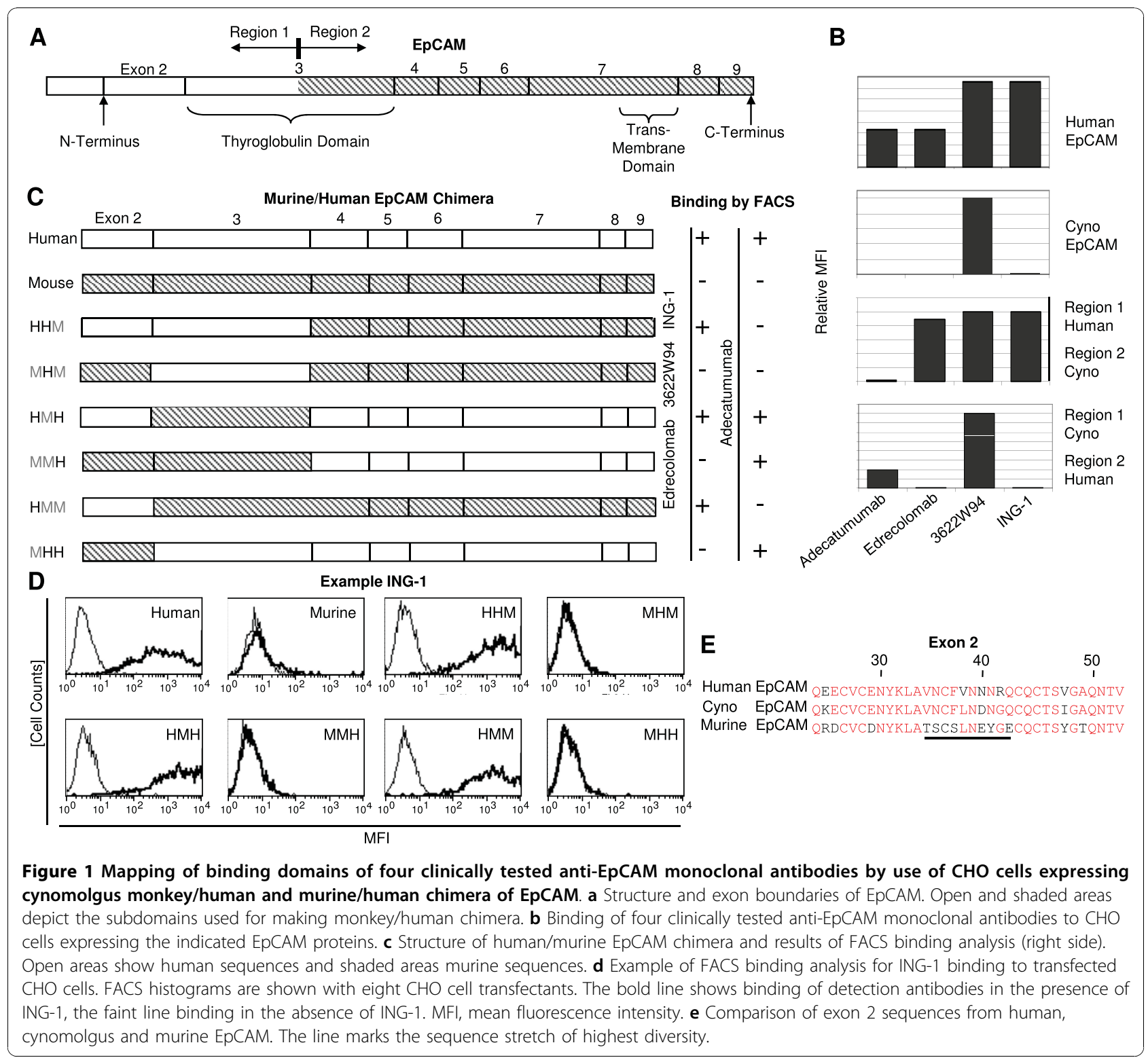

limited to sequences in exon 5 around amino acid position 170 (Figure 2a). The deviating amino acids in the monkey EpCAM protein, which is not recognized by adecatumumab, were changed by directed mutagenesis to the amino acids of the human ortholog (Figure 2b). Exchange of amino acids EEAIK in the monkey EpCAM protein to QKEIT, as is present in the human EpCAM protein, restored binding of adecatumumab to HEK293 cells (Figure 2c). The binding signal by FACS to cells expressing the QKEIT variant of monkey EpCAM was as strong as the signal seen with cells expressing human EpCAM. This gain of binding identifies a small sequence in exon 5 as the binding site for adecatumumab on human EpCAM. Two other mutations, DVQS to DSKS and ITNI to ITSI, did not restore binding of adecatumumab to cynomolgus monkey EpCAM (Figures 2b, c).

\section{ADCC Activity}

Target cell lysis by engagement of cytotoxic, Fc $\gamma$ receptor-expressing immune cells (ADCC) or by fixation of complement $(\mathrm{CDC})$ has been investigated for the five clinically tested anti-EpCAM antibodies. For ADCC, human peripheral blood mononuclear cells (PBMC) from five different healthy human donors were co-cultured with KATO III gastric carcinoma cells in the absence or presence of increasing concentrations of mAbs. Redirected lysis was monitored by release of a fluorescence dye from lysed cells. 


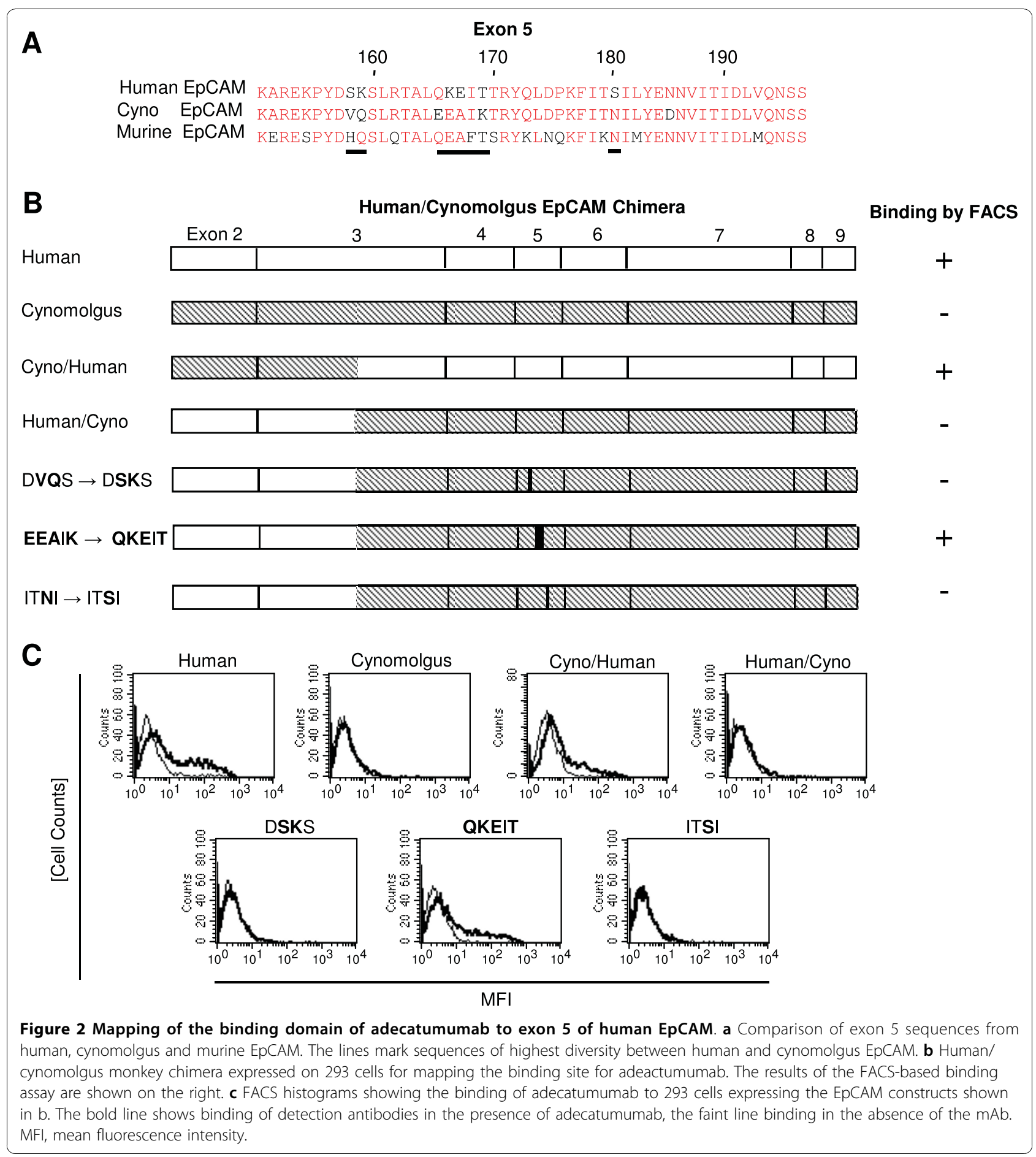

A considerable donor variation for ADCC was observed as expected for non age-matched PBMC donors (Tab. 2). ING-1 followed by 3622W94 showed the highest potency of ADCC with a mean $\mathrm{EC}_{50}$ value for redirected lysis of $14(0.76 \mathrm{nM})$ and $38 \mathrm{ng} / \mathrm{ml}(2.05 \mathrm{nM})$, respectively (Table 2). Examples for dose response curves obtained with two different donor PBMC are shown in Figure 3.
Close to complete lysis of target cells was observed with PBMC from donor 1, and approximately $50 \%$ lysis with PBMC from donor 2. Adceatumumab was also relatively potent with a mean $\mathrm{EC}_{50}$ value for redirected lysis of $175 \mathrm{ng} / \mathrm{ml}$ (9.45 nM). While murine/human chimeric edrecolomab was rather potent with a mean $\mathrm{EC}_{50}$ value of $671 \mathrm{ng} / \mathrm{ml}(36 \mathrm{nM})$ and reaching a similar percentage 
Table 2 ADCC by five clinically tested anti-EpCAM monoclonal antibodies.

\begin{tabular}{|c|c|c|c|c|c|c|}
\hline \multirow[t]{3}{*}{ Antibody } & \multicolumn{5}{|c|}{$\begin{array}{l}\text { Half-Maximum Lysis [ng/ml] } \\
\text { Maximum Lysis [Percent] }\end{array}$} & \multirow[t]{3}{*}{ Mean Half-Maximum Lysis $[\mathrm{ng} / \mathrm{ml}] \pm$ S.D } \\
\hline & \multirow[b]{2}{*}{1} & \multicolumn{3}{|c|}{ Donor } & \multirow[b]{2}{*}{5} & \\
\hline & & 2 & 3 & 4 & & \\
\hline \multirow[t]{2}{*}{ Edrecolomab } & 49 & n.d. & 21 & 917 & 68 & $264 \pm 436$ \\
\hline & $40 \%$ & n.d. & $24 \%$ & $37 \%$ & $16 \%$ & \\
\hline \multirow[t]{2}{*}{ Chimeric Edrecolomab } & 277 & 1.910 & 69 & 515 & 596 & $671 \pm 721$ \\
\hline & $84 \%$ & $43 \%$ & $19 \%$ & $94 \%$ & $44 \%$ & \\
\hline \multirow[t]{2}{*}{$3622 W 94$} & 4.5 & 102 & 2.0 & 4.9 & 79 & $38 \pm 48$ \\
\hline & $77 \%$ & $42 \%$ & $43 \%$ & $82 \%$ & $46 \%$ & \\
\hline \multirow[t]{2}{*}{ ING-1 } & 2.6 & 48 & 0.9 & 8.2 & 10 & $14 \pm 19$ \\
\hline & $90 \%$ & $47 \%$ & $23 \%$ & $78 \%$ & $54 \%$ & \\
\hline \multirow[t]{2}{*}{ Adecatumumab } & 50 & 537 & 11 & 100 & 176 & $175 \pm 211$ \\
\hline & $86 \%$ & $39 \%$ & $27 \%$ & $76 \%$ & $53 \%$ & \\
\hline
\end{tabular}

of cell lysis as 3622W94, ING-1 and adecatumumab, the murine IgG2a version of edrecolomab was barely active with PBMC from donor 1, and not active with PBMC from donor 2 (Figure 3). Although murine edrecolomab induced very low levels of $\mathrm{ADCC}$, its mean $\mathrm{EC}_{50}$ value was slightly lower than that of chimeric edrecolomab (Table 2).

\section{CDC Activity}

For CDC, 10\% human serum was added to KATO III gastric carcinoma cells and cell cultures incubated for $45 \mathrm{~min}$. For inactivation of complement, a fraction of human serum was heat-treated and used as control condition, along with human IgG1 and murine IgG2a isotype control antibodies. CDC was monitored by fluorescent dye release from lysed cells.
All five anti-EpCAM mABs showed specific complement-mediated lysis of cancer cells in the range of $30-55 \%$ at an antibody concentration of $20 \mu \mathrm{g} / \mathrm{ml}$ (Figure 4). At $2 \mu \mathrm{g} / \mathrm{ml} \mathrm{mAb}$, only the two high affinity mAbs 3622W94 and ING-1 gave CDC signals. ING-1 was the only mAb active at $0.2 \mu \mathrm{g} / \mathrm{ml}$. The two isotype control antibodies did not show significant CDC. In all cases, no CDC was observed with heat-treated human serum at the highest antibody concentration of $20 \mu \mathrm{g} / \mathrm{ml}$.

\section{A Minute but Significant Impact of Effect on Breast Cancer Cell Proliferation}

EpCAM was recently shown to have oncogenic potential and nuclear signalling activity in cancer cells [14], and to induce upon overexpression the proliferation of quiescent cells via c-myc [15]. Breast cancer cell line MCF-7

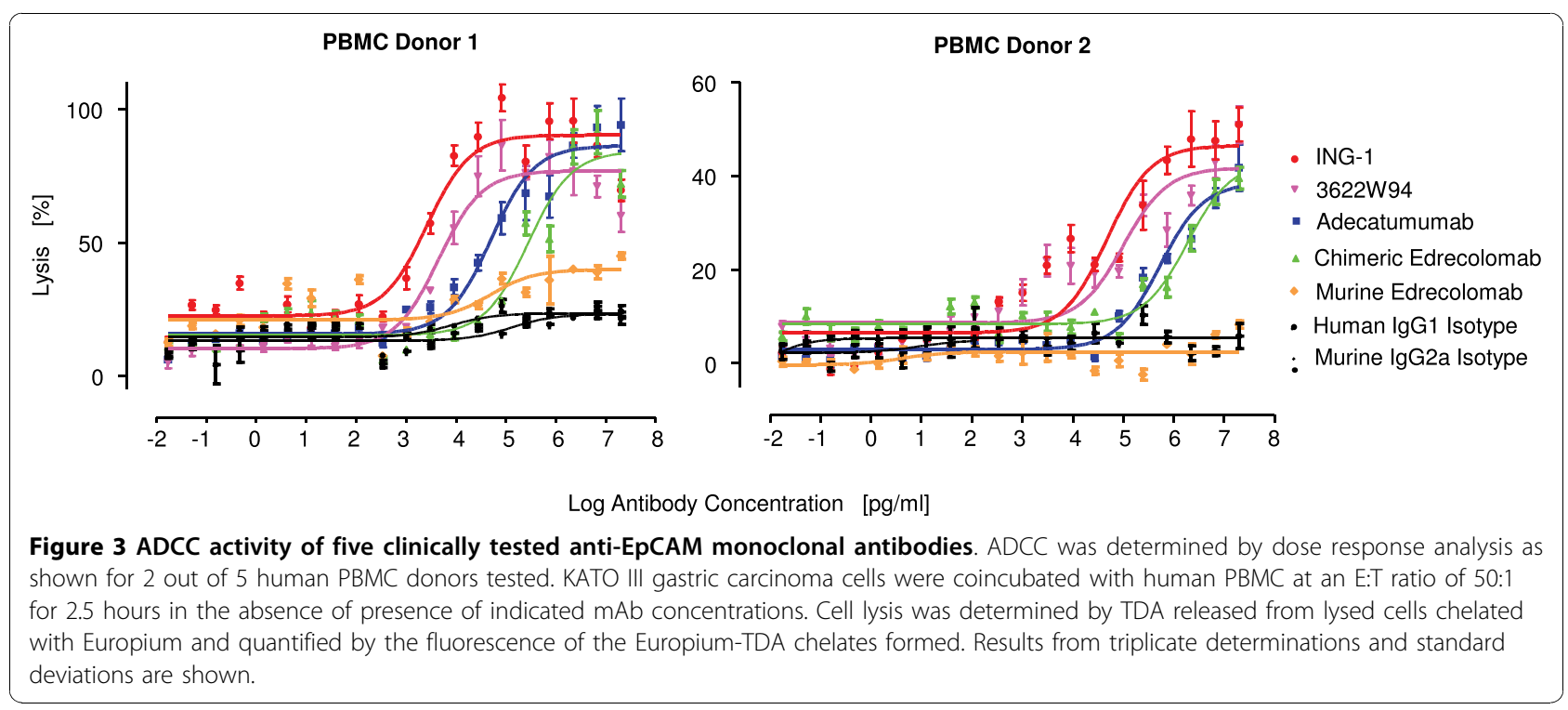




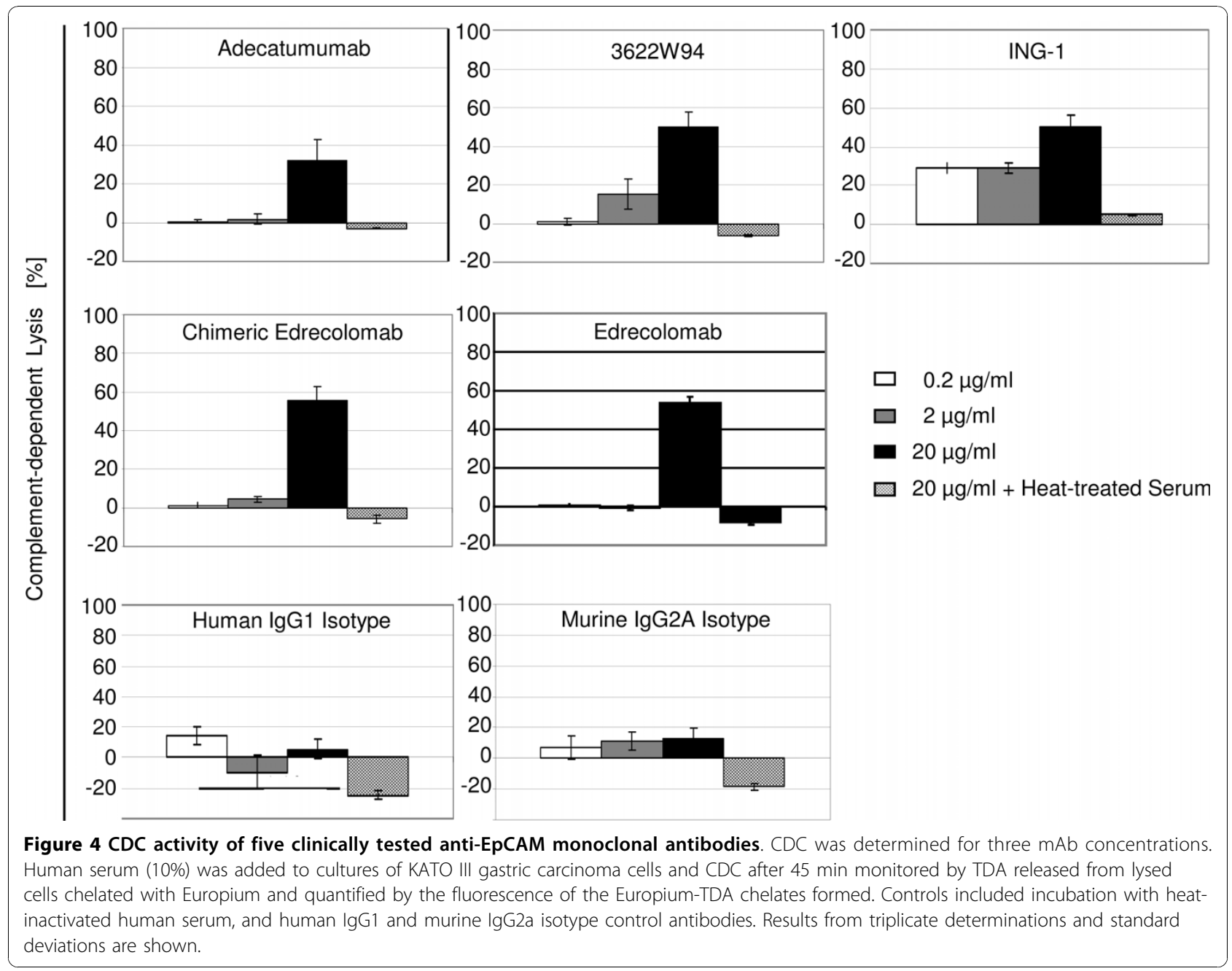

has been identified by knockdown experiments as being dependent on EpCAM for proliferation [13], which is why it was here selected for further characterization of antibodies. We tested the five $\mathrm{mAbs}$ at $50 \mu \mathrm{g} / \mathrm{ml}$ in cell culture for effects on the metabolism of breast cancer cell line MCF-7 and normal breast epithelial cell line MCF10A. Only adecatumumab showed a small but significant inhibitory effect on cell metabolism using a WST-1 assay (data not shown). It was the only mAb that showed after 3 days a significant 50\% inhibition of MCF7 cell proliferation when compared to a human IgG1 isotype control antibody (Figure 5a and 5b). Proliferation of normal breast epithelial cell line MCF10A was not significantly affected by any of the anti-EpCAM mAbs, including adecatumumab (Figure $5 b$ ).

\section{Discussion}

Here we report the first side-by-side comparison of five clinically tested anti-EpCAM monoclonal antibodies. With the exception of adecatumumab and edrecolomab,
mAbs were newly constructed by recombinant technology, produced by $\mathrm{CHO}$ cell clones and purified by a standard procedure. Their production in $\mathrm{CHO}$ cells may deviate from that in cell systems used for production of respective clinical test materials. As a consequence, certain mAbs investigated in the present study may differ in their carbohydrate composition from the clinically tested antibodies. Carbohydrates are known to influence ADCC and CDC activities of antibodies [49]. Hence results from ADCC and CDC assays have to be interpreted with caution. On the other hand, our standardized production of mAbs may allow for a better comparison of in-vitro properties than using clinical test samples, which are difficult to procure. N-linked carbohydrate structures as attached to the $\mathrm{CH} 2$ domain of IgG may be very similar among our four $\mathrm{CHO}$-produced mAbs and, moreover, are not expected to impact binding affinity and specificity of the mAbs for the EpCAM antigen.

The most significant differences among edrecolomab, 3622W94, ING-1 and adecatumumab were found in their 


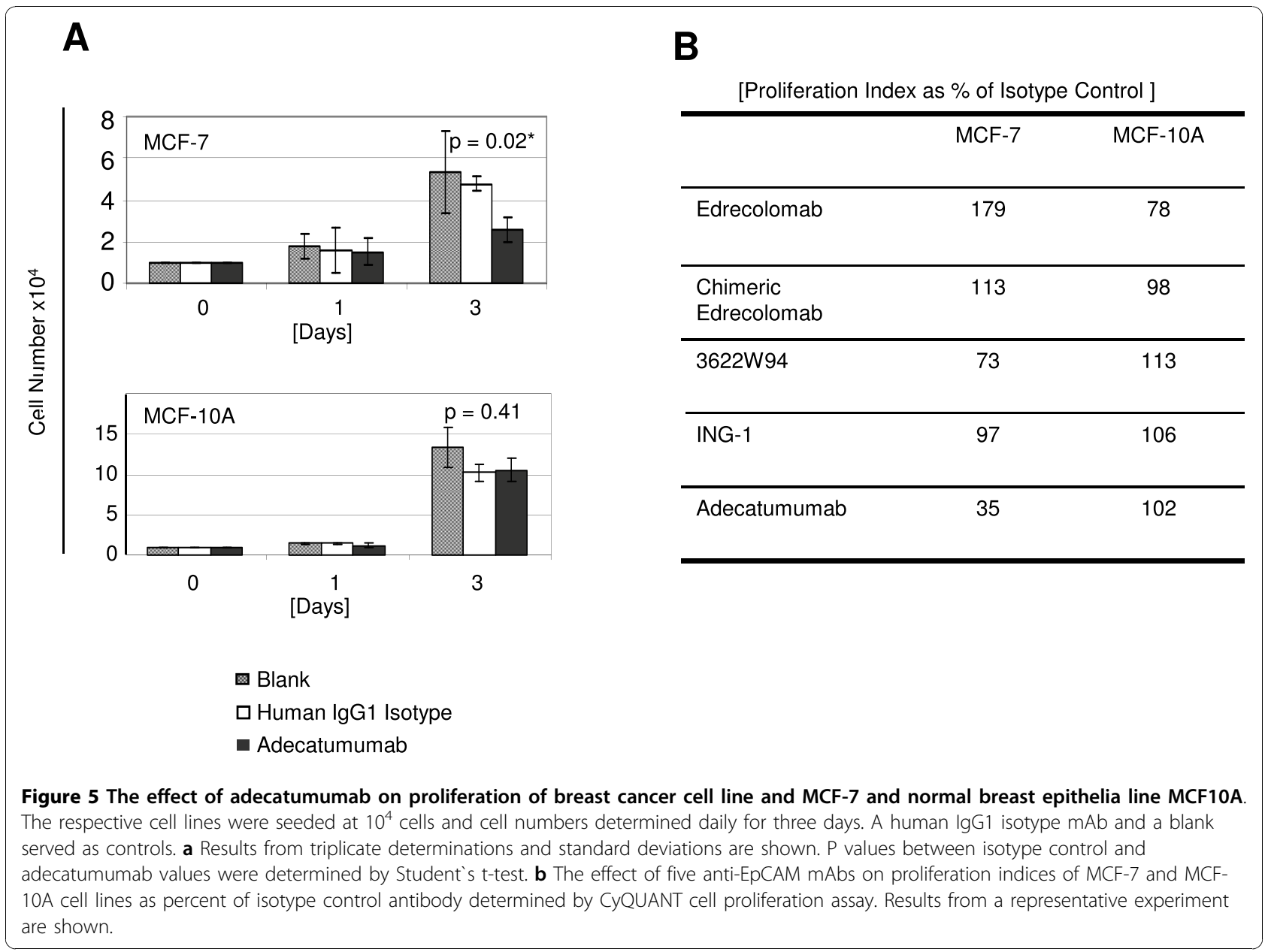

binding affinities and binding epitopes. Affinity constants derived from plasmon resonance analysis using immobilized, recombinant EpCAM protein matched well with values previously published for the mAbs. The binding epitopes of edrecolomab, 3622W94 and ING-1 are likely to be all contained in a short $\mathrm{N}$-terminal sequence of EpCAM encoded by exon 2. In this sequence (see Figure 1e), position 42 is most divergent and therefore may best explain why cynomolgus EpCAM is not recognized by edrecolomab and ING-1, but by 3622W94, which may not depend on position 42 for binding. Future point mutation analyses are required to define the binding epitopes in greater detail. The binding epitope of adecatumumab was contained in a more membrane-proximal, exon 5-encoded sequence of human EpCAM (see Figure 2 ). Gain of antibody binding by replacing the short sequence EEAIK in cynomolgus EpCAM with the short human sequence QKEIT identifies the latter as part of the binding epitope for adecatumumab. Binding of adecatumumab to a different domain of EpCAM than recognized by the other mAbs apparently did not affect ADCC or CDC activity. It may, however, affect binding of the antibody to EpCAM on normal tissues, which may translate into a higher tolerability than reported for ING-1 and 3622W94. The much slower off-rates of ING-1 and 3622W94 compared to adecatumumab and edrecolomab may likewise determine the therapeutic window and antitumor activity. High-affinity antibodies were shown to poorly penetrate into tumor tissue while an affinity of $10^{-}$ ${ }^{7}-10^{-8} \mathrm{M}$, as observed here for adecatumumab, was optimal for tumor penetration of anti-Her-2/neu single-chain antibodies [50].

All four human IgG1 mAbs showed robust ADCC activity leading to similar degrees of target cell lysis at the plateau of dose response curves. However, their $\mathrm{EC}_{50}$ values for redirected lysis were different and appeared to correlate with their respective binding affinities as determined by plasmon resonance spectroscopy. In addition, $\mathrm{EC}_{50}$ values showed considerable variation for two non age-matched PBMC donors. It has been reported that CD56-positive natural killer (NK) cells are the main effector population causing ADCC by anti-EpCAM antibody adecatumumab[51]. Elder donors were found to have higher amounts of NK cells but 
with lower activity compared to younger donors [52]. Here we paid attention to using the same donor PBMC for comparing all antibodies. Although the two PBMC donors gave different $\mathrm{EC}_{50}$ values for $\mathrm{ADCC}$ for each antibody the overall ranking of the antibodies' ADCC was conserved, suggesting that differences among the antibodies were not due to donor variation but to instrinsic properties. The murine version of edrecolomab performed poorest in ADCC with human effector cells. This may be due to a reduced compatibility of its murine Fc $\gamma 2 \mathrm{a}$ portion with Fc $\gamma$ receptors on human immune effector cells. This notion has recently been demonstrated by comparing 'murinized' IgG2a and human IgG1 versions of adecatumumab [53].

At $20 \mu \mathrm{g} / \mathrm{ml}$, all five mAbs showed robust and comparable levels of CDC during a 45-min assay. Only ING-1 and 3622W94 showed CDC at lower antibody concentrations, which again are in line with their higher binding affinity as seen in Biacore analyses. As reported earlier, adecatumumab and murine edrecolomab showed equal CDC [42], whereas other investigators could not detect any CDC for murine or chimeric edrecolomab [54]. Our data indicate that all but murine edrecolomab should be able to eliminate cancer cells in patients by both ADCC and CDC.

The findings that EpCAM is a proto-oncogene and signal transducer $[9,14,15]$ raise the possibility that antiEpCAM antibodies may be able to interfere with the proliferative signal transduction cascade initiated by EpCAM. Of all five mAbs tested, only adecatumumab could specifically and significantly reduce proliferation of breast cancer cell line MCF-7 but not of normal epithelial cell line MCF10A. EpCAM knockdown experiments in MCF-7 cells have shown that cells cease to proliferate, migrate and invade soft agar, indicating that this cancer cell line is dependent on EpCAM signalling [13]. Future studies will investigate whether the binding of adecatumumab to its membrane-proximal epitope interferes with proteolytic activation of EpCAM. At the same time, it can be studied whether murine edrecolomab is promoting the proteolytic activation of EpCAM leading to the higher proliferation index observed here for MCF-7 cells. It is tempting to speculate that the unique binding specificity of adecatumumab, its not overly high affinity, robust ADCC and CDC, and its inhibitory effect on cell proliferation may in their combination be important for producing signs of clinical activity and a good tolerability in more than 240 patients treated to date $[43,45,46]$.

\section{Conclusions}

From the present in-vitro data, the induction of acute pancreatitis by mAbs 3622 W94 and ING-1 is best explained by their high binding affinities for EpCAM seen in Biacore analyses, in particular their very slow off-rates. High binding affinities may also best explain their superior CDC and ADCC activities at low concentrations. With a high affinity and slow off-rate, such antibodies could very well reach a surface density on cells of normal tissue, which is sufficient to trigger ADCC and CDC reactions even if low numbers of EpCAM molecules are accessible. Should EpCAM on normal tissue be mostly in complex with protein partners, e.g., with claudin-7, tetraspanins or CD44, high affinity antibodies may compete for their binding to EpCAM and permanently displace EpCAM-associated proteins while antibodies with lower affinity should be inefficient to do so.

\section{Author details}

${ }^{1}$ Micromet AG, Staffelseestr. 2, 81477 Munich, Germany. ${ }^{2}$ Micromet, Inc. 6707 Democracy Blvd., Bethesda, MD 20817, USA. ${ }^{3}$ Institute for Immunology, Ludwig-Maximilians University, Goethestr. 31, 81333 Munich, Germany.

\section{Authors' contributions}

MM conceived the study, participated in its design and coordination, and wrote a first draft of the manuscript. AM performed most of the experiments. MK carried out the biacore analysis. DRa, SM, SP, JL, JV participated in the molecular cloning of antibodies and FACS analyses. JF, GR and DRu provided critical input to the manuscript. PK and TR participated in the coordination of the study and participated in its design. $\mathrm{PB}$ conceived the study together with $\mathrm{MM}$, and finalized the mansucript. All authors read and approved the final manuscript.

\section{Competing interests}

MM, AM, MK, DRa, SM, SP, JL, JV, JF, GR, DRu, PK, PB and TR are employees of Micromet, Inc., and have equity positions in the company. Micromet is focused on the development of BiTE antibodies for the treatment of malignant diseases.

The present study has not been used for a new patent filing. Funding of this study has been supplied by Micromet Inc., a publically listed company.

Received: 4 May 2010 Accepted: 2 November 2010

Published: 2 November 2010

\section{References}

1. Baeuerle PA, Gires O: EpCAM (CD326) finding its role in cancer. $\mathrm{Br} J$ Cancer 2007, 96(3):417-423.

2. Herlyn M, Steplewski Z, Herlyn D, Koprowski H: Colorectal carcinomaspecific antigen: detection by means of monoclonal antibodies. Proc Natl Acad Sci USA 1979, 76(3):1438-1442.

3. Trzpis M, McLaughlin PM, de Leij LM, Harmsen MC: Epithelial cell adhesion molecule: more than a carcinoma marker and adhesion molecule. Am J Pathol 2007, 171(2):386-395.

4. Epenetos AA, Nimmon CC, Arklie J, Elliott AT, Hawkins LA, Knowles RW, Britton KE, Bodmer WF: Detection of human cancer in an animal model using radio-labelled tumour-associated monoclonal antibodies. $\mathrm{Br} \mathrm{J}$ Cancer 1982, 46(1):1-8.

5. Litvinov SV, Velders MP, Bakker HA, Fleuren GJ, Warnaar SO: Ep-CAM: a human epithelial antigen is a homophilic cell-cell adhesion molecule. J Cell Biol 1994, 125(2):437-446.

6. Litvinov SV, Bakker HA, Gourevitch MM, Velders MP, Warnaar SO: Evidence for a role of the epithelial glycoprotein 40 (Ep-CAM) in epithelial cell-cell adhesion. Cell Adhes Commun 1994, 2(5):417-428.

7. Balzar M, Briaire-de Bruijn $H_{\text {, }}$ Rees-Bakker HA, Prins FA, Helfrich W, de Leij L, Riethmuller G, Alberti S, Warnaar SO, Fleuren GJ, et al: Epidermal growth factor-like repeats mediate lateral and reciprocal interactions of Ep-CAM molecules in homophilic adhesions. Mol Cell Biol 2001, 21(7):2570-2580. 
8. Stoecklein NH, Siegmund A, Scheunemann P, Luebke AM, Erbersdobler A, Verde PE, Eisenberger CF, Peiper M, Rehders A, Esch JS, et al: Ep-CAM expression in squamous cell carcinoma of the esophagus: a potential therapeutic target and prognostic marker. BMC Cancer 2006, 6:165.

9. Munz M, Baeuerle PA, Gires O: The emerging role of EpCAM in cancer and stem cell signaling. Cancer Res 2009, 69(14):5627-5629.

10. Gires $\mathrm{O}$, Klein CA, Baeuerle PA: On the abundance of EpCAM on cancer stem cells. Nat Rev Cancer 2009, 9(2):143, author reply 143.

11. Visvader JE, Lindeman GJ: Cancer stem cells in solid tumours: accumulating evidence and unresolved questions. Nat Rev Cancer 2008, 8(10):755-768

12. Marhaba R, Klingbeil $P$, Nuebel T, Nazarenko I, Buechler MW, Zoeller M: CD44 and EpCAM: cancer-initiating cell markers. Curr Mol Med 2008, 8(8):784-804

13. Osta WA, Chen Y, Mikhitarian K, Mitas M, Salem M, Hannun YA, Cole DJ, Gillanders WE: EpCAM is overexpressed in breast cancer and is a potential target for breast cancer gene therapy. Cancer Res 2004, 64(16):5818-5824.

14. Maetzel D, Denzel S, Mack B, Canis M, Went P, Benk M, Kieu C, Papior P, Baeuerle PA, Munz $M$, et al: Nuclear signalling by tumour-associated antigen EpCAM. Nat Cell Biol 2009, 11(2):162-171.

15. Munz M, Kieu C, Mack B, Schmitt B, Zeidler R, Gires O: The carcinomaassociated antigen EpCAM upregulates c-myc and induces cell proliferation. Oncogene 2004, 23(34):5748-5758.

16. Gonzalez B, Denzel S, Mack B, Conrad M, Gires O: EpCAM is involved in maintenance of the murine embryonic stem cell phenotype. Stem Cells 2009, 27(8):1782-1791.

17. Leon J, Ferrandiz N, Acosta JC, Delgado MD: Inhibition of cell differentiation: a critical mechanism for MYC-mediated carcinogenesis? Cell Cycle 2009, 8(8):1148-1157.

18. Wang J, Wang H, Li Z, Wu Q, Lathia JD, McLendon RE, Hjelmeland AB, Rich JN: c-Myc is required for maintenance of glioma cancer stem cells. PLoS One 2008, 3(11):e3769.

19. Zeilstra J, Joosten SP, Dokter M, Verwiel E, Spaargaren M, Pals ST: Deletion of the WNT target and cancer stem cell marker CD44 in Apc(Min/+) mice attenuates intestinal tumorigenesis. Cancer Res 2008, 68(10):3655-3661.

20. Yamashita T, Budhu A, Forgues M, Wang XW: Activation of hepatic stem cell marker EpCAM by Wnt-beta-catenin signaling in hepatocellular carcinoma. Cancer Res 2007, 67(22):10831-10839.

21. Chaudry MA, Sales K, Ruf $P$, Lindhofer $H$, Winslet MC: EpCAM an immunotherapeutic target for gastrointestinal malignancy: current experience and future challenges. Br J Cancer 2007, 96(7):1013-1019.

22. Freitag H, Gress G, Messer K, Sivaz G, Weinbender O, Zundorf I, Dingermann T: Bitte ein BiTE((R)). Pharm Unserer Zeit 2009, 38(5):396-398.

23. Münz $M$, Herrmann I, Friedrich $M$, Murr A, Kufer $P$, Baeuerle $P$, Raum T: Eradication of colon cancer stem cells by EpCAM/CD3-bispecific BiTE antibody MT110. AACR 2009 2009, 3250.

24. Sears HF, Herlyn D, Steplewski Z, Koprowski H: Effects of monoclonal antibody immunotherapy on patients with gastrointestinal adenocarcinoma. J Biol Response Mod 1984, 3(2):138-150.

25. Sears HF, Atkinson B, Mattis J, Ernst C, Herlyn D, Steplewski Z, Hayry P, Koprowski $\mathrm{H}$ : Phase-I clinical trial of monoclonal antibody in treatment of gastrointestinal tumours. Lancet 1982, 1(8275):762-765.

26. Ragnhammar P, Fagerberg J, Frodin JE, Hjelm AL, Lindemalm C, Magnusson I, Masucci G, Mellstedt H: Effect of monoclonal antibody 17$1 \mathrm{~A}$ and GM-CSF in patients with advanced colorectal carcinoma-longlasting, complete remissions can be induced. Int J Cancer 1993, 53(5):751-758.

27. Riethmuller G, Schneider-Gadicke E, Schlimok G, Schmiegel W, Raab R, Hoffken K, Gruber R, Pichlmaier H, Hirche H, Pichlmayr R, et al: Randomised trial of monoclonal antibody for adjuvant therapy of resected Dukes' $\mathrm{C}$ colorectal carcinoma. German Cancer Aid 17-1A Study Group. Lancet 1994, 343(8907):1177-1183.

28. Riethmuller G, Holz E, Schlimok G, Schmiegel W, Raab R, Hoffken K, Gruber R, Funke I, Pichlmaier $\mathrm{H}$, Hirche $\mathrm{H}$, et al: Monoclonal antibody therapy for resected Dukes' C colorectal cancer: seven-year outcome of a multicenter randomized trial. J Clin Oncol 1998, 16(5):1788-1794.

29. Goldberg RM: Lessons learned from the edrecolomab story: how a checkered past became a checkered flag for monoclonal antibodies in colorectal cancer therapy. Onkologie 2005, 28(6-7):311-312.
30. Fields AL, Keller A, Schwartzberg L, Bernard S, Kardinal C, Cohen A, Schulz J, Eisenberg P, Forster J, Wissel P: Adjuvant therapy with the monoclonal antibody Edrecolomab plus fluorouracil-based therapy does not improve overall survival of patients with stage III colon cancer. J Clin Oncol 2009, 27(12):1941-1947.

31. Schmoll HJ, Arnold D: When wishful thinking leads to a misty-eyed appraisal: the story of the adjuvant colon cancer trials with edrecolomab. J Clin Oncol 2009, 27(12):1926-1929.

32. Shaw DR, Khazaeli MB, LoBuglio AF: Mouse/human chimeric antibodies to a tumor-associated antigen: biologic activity of the four human lgG subclasses. J Natl Cancer Inst 1988, 80(19):1553-1559.

33. Weiner LM: Building better magic bullets-improving unconjugated monoclonal antibody therapy for cancer. Nat Rev Cancer 2007, 7(9):701-706.

34. Siberil S, Dutertre CA, Fridman WH, Teillaud JL: FcgammaR: The key to optimize therapeutic antibodies? Crit Rev Oncol Hematol 2007, 62(1):26-33.

35. Liljefors M, Nilsson B, Fagerberg J, Ragnhammar P, Mellstedt H, Frodin JE: Clinical effects of a chimeric anti-EpCAM monoclonal antibody in combination with granulocyte-macrophage colony-stimulating factor in patients with metastatic colorectal carcinoma. Int J Oncol 2005, 26(6):1581-1589.

36. Fagerberg J, Ragnhammar P, Liljefors M, Hjelm AL, Mellstedt H, Frodin JE: Humoral anti-idiotypic and anti-anti-idiotypic immune response in cancer patients treated with monoclonal antibody 17-1A. Cancer Immunol Immunother 1996, 42(2):81-87.

37. Gruber R, van Haarlem LJ, Warnaar SO, Holz E, Riethmuller G: The human antimouse immunoglobulin response and the anti-idiotypic network have no influence on clinical outcome in patients with minimal residual colorectal cancer treated with monoclonal antibody CO17-1A. Cancer Res 2000, 60(7):1921-1926.

38. Goel S, Bauer RJ, Desai K, Bulgaru A, lqbal T, Strachan BK, Kim G, Kaubisch A, Vanhove GF, Goldberg G, et al: Pharmacokinetic and safety study of subcutaneously administered weekly ING-1, a human engineere monoclonal antibody targeting human EpCAM, in patients with advanced solid tumors. Ann Oncol 2007, 18(10):1704-1707.

39. Lewis LD: Technology evaluation: ING-1, XOMA. Curr Opin Mol Ther 2003 5(4):433-436

40. Saleh M, Posey J, Khazaeli M, Thurmond L, Khor S, Lampkin T, Wissel P, LoBuglio A: Phase I Trial Testing Multiple Doses Of Humanized Monoclonal Antibody (MAb) 3622W94 (Meeting abstract). ASCO 1998, 1680.

41. LoBuglio A, Saleh M, Braddock J, et al: A phase I trial of the humanized anti-EGP40 monoclonal antibody 3622W94 [abstract]. Proc Am Soc Clin Oncol 16 1997, 16:436.

42. Naundorf $S$, Preithner $S$, Mayer $P$, Lippold S, Wolf A, Hanakam F, Fichtner I, Kufer $P$, Raum T, Riethmuller $G$, et al: In vitro and in vivo activity of MT201, a fully human monoclonal antibody for pancarcinoma treatment. Int J Cancer 2002, 100(1):101-110.

43. Oberneder R, Weckermann D, Ebner B, Quadt C, Kirchinger P, Raum T, Locher M, Prang N, Baeuerle PA, Leo E: A phase I study with adecatumumab, a human antibody directed against epithelial cell adhesion molecule, in hormone refractory prostate cancer patients. Eur J Cancer 2006, 42(15):2530-2538.

44. Kirman I, Whelan RL: Drug evaluation: adecatumumab, an engineered human anti-EpCAM antibody. Curr Opin Mol Ther 2007, 9(2):190-196.

45. Schmidt M, Scheulen ME, Dittrich C, Obrist P, Marschner N, Dirix L, Ruttinger D, Schuler M, Reinhardt C, Awada A: An open-label, randomized phase II study of adecatumumab, a fully human anti-EpCAM antibody, as monotherapy in patients with metastatic breast cancer. Ann Oncol 2010, 21(2):275-282.

46. Schuler $M$, et al: First results from a phase $\mathrm{lb}$ study of the anti-EpCAM antibody adecatumumab (MT201) in combination with docetaxel in patients with metastatic breast cancer. Annual Meeting of ESMO 2008, Abstract No. 485p.

47. Sebastian M, et al: Safety and anti-tumor activity of 3-weekly anti-EpCAM antibody adecatumumab (MT201) in combination with docetaxel for patients with metastatic breast cancer: Results of a multicenter phase $\mathrm{lb}$ trial. ASCO meeting 2009, abstract no. 1009.

48. Raum T, Gruber R, Riethmuller G, Kufer P: Anti-self antibodies selected from a human IgD heavy chain repertoire: a novel approach to generate 
therapeutic human antibodies against tumor-associated differentiation antigens. Cancer Immunol Immunother 2001, 50(3):141-150.

49. Raju TS: Terminal sugars of Fc glycans influence antibody effector functions of IgGs. Curr Opin Immunol 2008, 20(4):471-478.

50. Adams GP, Schier R, McCall AM, Simmons HH, Horak EM, Alpaugh RK, Marks JD, Weiner LM: High affinity restricts the localization and tumor penetration of single-chain fv antibody molecules. Cancer Res 2001, 61(12):4750-4755.

51. Preithner S, Elm S, Lippold S, Locher M, Wolf A, da Silva AJ, Baeuerle PA Prang NS: High concentrations of therapeutic lgG1 antibodies are needed to compensate for inhibition of antibody-dependent cellular cytotoxicity by excess endogenous immunoglobulin G. Mol Immunol 2006, 43(8):1183-1193.

52. Malaguarnera L, Ferlito L, Imbesi RM, Gulizia GS, Di Mauro S, Maugeri D, Malaguarnera M, Messina A: Immunosenescence: a review. Arch Gerontol Geriatr 2001, 32(1):1-14

53. Lutterbuese $P$, Brischwein $K$, Hofmeister R, Crommer S, Lorenczewski $G$, Petersen L, Lippold S, da Silva A, Locher M, Baeuerle PA, et al: Exchanging human Fcgamma1 with murine Fcgamma2a highly potentiates antitumor activity of anti-EpCAM antibody adecatumumab in a syngeneic mouse lung metastasis model. Cancer Immunol Immunother 2007, 56(4):459-468.

54. Shaw DR, Khazaeli MB, Sun LK, Ghrayeb J, Daddona PE, McKinney S, LoBuglio AF: Characterization of a mouse/human chimeric monoclonal antibody (17-1A) to a colon cancer tumor-associated antigen. J Immunol 1987, 138(12):4534-4538.

doi:10.1186/1475-2867-10-44

Cite this article as: Münz et al:: Side-by-side analysis of five clinically tested anti-EpCAM monoclonal antibodies. Cancer Cell International 2010 10:44.

\section{Submit your next manuscript to BioMed Central and take full advantage of:}

- Convenient online submission

- Thorough peer review

- No space constraints or color figure charges

- Immediate publication on acceptance

- Inclusion in PubMed, CAS, Scopus and Google Scholar

- Research which is freely available for redistribution

Submit your manuscript at www.biomedcentral.com/submit 